\section{RESPONSABILIDADE SOCIAL UNIVERSITÁRIA LEVINASIANA E A FORMAÇÃO DA CONSCIÊNCIA SOCIAL SOB O OLHAR DE DISCENTES DE SECRETARIADO EXECUTIVO}

\author{
LEVINASIAN UNIVERSITY SOCIAL \\ RESPONSIBILITY AND THE FORMATION OF \\ SOCIAL CONSCIENCE FROM THE POINT OF \\ VIEW OF EXECUTIVE SECRETARIAT STUDENTS
}

\section{RESUMO}

Este trabalho tem por objetivo analisar as contribuições da participação em ações de Responsabilidade Social Universitária, na perspectiva levinasiana, para a formação da consciência social, na percepção de discentes de Secretariado Executivo. Para tanto, foi realizada uma pesquisa qualitativa e descritiva, por meio de um levantamento teórico e um estudo de campo com a participação de quatro representantes discentes do curso de Secretariado Executivo da Universidade Federal do Ceará. Como técnica de pesquisa, definiu-se a entrevista reflexiva e utilizou-se um roteiro, como instrumento de coleta de dados. Para a análise das informações, recorreu-se à técnica de análise reflexiva. Concluiu-se que participar de ações de Responsabilidade Social Universitária proporciona contato com o diferente e, dessa forma, o sujeito amplia sua visão sobre a sociedade, gera alteridade e respeito às diferenças e senso de responsabilidade para com o Outro, culminando no desenvolvimento de uma consciência social.

Palavras-chave: Responsabilidade Social Universitária. Consciência Social. Secretariado Executivo.

Conceição de Maria Pinheiro

Barros

conceicaompb@ufc.com.br

Doutora em Educação, pela Universidade Estadual do Ceará (UECE). Professora Adjunta da Universidade Federal do Ceará (UFC). Fortaleza - CE - BR.

Sara Costa Gonçalves saracostag4@gmail.com Bacharela em Secretariado Executivo pela Universidade Federal do Ceará. Fortaleza $C E-B R$.

\begin{abstract}
This work aims to analyze the contributions of participation in actions of University Social Responsibility, from the Levinasian perspective, for the formation of social counciousness, in the perception of students of Executive Secretariat. For this, a qualitative and descriptive research was carried out, through a theoretical survey and a field study with the participation of four student representatives of the Executive Secretariat course at the Federal University of Ceará. As a research technique, a reflexive interview was
\end{abstract}


defined and a script was used as an instrument for data collection. The technique of reflective analysis was used to analyze the information. It was concluded that participating in University Social Responsibility actions provides contact with the different and, in this way, the subject broadens his vision of society, generates otherness and respect for differences and sense of responsibility towards the Other, culminating in the development of a social consciousness.

Keywords: University Social Responsibility. Social Consciousness. Executive Secretariat.

\section{INTRODUÇÃO}

A responsabilidade social se efetiva na construção da cidadania, na qual, com uma perspectiva transdisciplinar de atuação pedagógica e profissional, ocorre a circulação e o entrelaçamento de saberes acadêmicos e populares, em um processo singular de aprendizagem e de produção de conhecimento em torno dos desafios emancipatórios da sociedade. $\mathrm{O}$ entendimento de Responsabilidade Social discutido nesta investigação distancia-se da ideia empresarial que "[...] é considerada crucial para um melhor entendimento sobre os impactos da atividade econômica na sociedade" (JORDÃO, 2019, p. 23). A perspectiva de Responsabilidade Social Universitária (RSU) abordada tem por base a perspectiva levinasiana, que considera a responsabilidade por outrem "à medida que tenho que responder não só pelo rosto do outro homem, mas, que, ao lado dele, abordo o terceiro [...]" (LÉVINAS, 2005, p. 143). Exercer responsabilidade pelo próximo assume caráter de obrigação ética. Na esteira do pensamento de Lévinas (2005, p. 138), "para uma sensibilidade ética - que se confirma, na inumanidade de nosso tempo, contra essa inumanidade - a justificação da dor do próximo é, certamente, a fonte de toda imoralidade". Por ser o meio formador de opiniões, a educação é considerada por Barros (2009, p. 25) como "[...] o caminho a ser seguido rumo à concretização do dever ético."

Com efeito, educação, ética e responsabilidade social se interligam, pois, nos espaços educativos, constitui-se e problematiza-se a participação do indivíduo na vida pública, o que demanda a consciência de realidades, conflitos e interesses individuais e sociais, o conhecimento de mecanismos de controle e defesa de direitos e a noção dos limites e das possibilidades de ações individuais e coletivas, formando uma consciência social. Para Peirce, "[...] a consciência não pertence ao ser humano, mas, sim, o ser humano pertence à consciência. A doutrina da continuidade constitui importante ponto de partida para se pensar a consciência" (ZULIANI, 2011, p. 7). O desenvolvimento de uma consciência é "[...] um comportamento que vem de uma convicção interna, que não tem dúvidas de que o que fizer para o outro, fará para si mesmo" (ZULIANI, 2011, p. 75-76). Ela se manifesta, em determinados momentos, no usual sentimento de simpatia para com a condição de Outro ${ }^{1}$ ser. Esse processo pode ser explicado "[...] pelo princípio da continuidade, aplicada ao surgimento de mentes individuais em um universo de generalidade relacional"' (ZULIANI, 2011, p. 50). Para Lévinas (1998), porém, a relação com o Outro ultrapassa a simpatia, trata-se da obrigação de acolher outrem em sua alteridade e responsabilizar-se por ele.

Com sustento nessas concepções, entende-se como Responsabilidade Social Universitária levinasiana a obrigação que a universidade encerra de oferecer respostas à sociedade por meio da formação da consciência social de futuros profissionais. Nessa perspectiva, a sociedade é considerada Outro da universidade (BARROS; FREIRE, 2011). Esta pesquisa visa responder à seguinte questão norteadora: de que maneira a Responsabilidade Social Universitária, na perspectiva

1 A maioria dos textos levinasianos utiliza a expressão "Outro" com inicial maiúscula. Optou-se por utilizar esse formato para salientar a sua valorização na perspectiva da ética da alteridade radical. 
levinasiana, contribui para a formação da consciência social? Pressupõe-se que a Universidade por ser o lócus para a formação de profissionais responsáveis, éticos e cidadãos, também forma para uma consciência social, mediante a participação dos discentes em ações de responsabilidade social.

Esta pesquisa tem como objetivo analisar as contribuições da participação em ações de Responsabilidade Social Universitária, na perspectiva levinasiana, para a formação da consciência social, na percepção de discentes de Secretariado Executivo. No âmbito da universidade, são construídos conhecimentos e experiências que ultrapassam os limites do saber intelectual e adentram na formação social e cidadã. A universidade, por ser agência social especializada em conhecimento e educação que contém relação direta com a busca pela construção de um mundo mais equitativo e com melhores condições sociais, econômicas, intelectuais, culturais e ambientais para todos, é o espaço apropriado para pensar, discutir e fazer propostas (JULIATTO, 2004). Destarte, a universidade não pode ausentar-se de oferecer respostas ou apresentar reflexões quanto às demandas sociais.

O estudo sobre o tema está longe de ser considerado saturado, o que torna o tema relevante para a área secretarial, servindo de referência para pesquisas futuras. Ao realizar um levantamento no site da Coordenação de Aperfeiçoamento de Pessoal de Nível Superior (CAPES), utilizando as palavras-chave "Responsabilidade Social", e "Secretariado Executivo", para delimitar o assunto e o título, foram encontrados seis resultados: quatro estudos na área da responsabilidade social corporativa e duas pesquisas voltadas para responsabilidade socioambiental. Discutir a consciência social, à luz da RSU na formação em Secretariado Executivo, pode promover discussões acerca de inquietações originadas nas interações que ele faz com a comunidade interna e externa, assim como novos questionamentos e reflexões acerca do tema.

\section{A RESPONSABILIDADE SOCIAL LEVINASIANA E A FORMAÇÃO DA CONSCIÊNCIA SOCIAL EM SECRETARIADO EXECUTIVO}

\subsection{A RESPONSABILIDADE SOCIAL UNIVERSITÁRIA NA PERSPECTIVA DA ÉTICA DA ALTERIDADE RADICAL}

O pensamento levinasiano, segundo Barros (2009), salienta o liame do homem com os outros homens, por intermédio do discernimento de mundo exterior. Lévinas (2005) explica esse discernimento fundado no reconhecimento do "ser pensante" e do "puro vivente". "O que o pensante percebe como exterioridade que convida ao trabalho é a apropriação, o vivente o experimenta como sua substância, como consubstancial a ele [...]" (LÉVINAS, 2005, p. 34). O "puro vivente" não conhece o mundo exterior, o fato ocorre no instante em que o indivíduo não avalia o que ocorre à sua volta. Lévinas (2005, p. 35-36) salienta:

\begin{abstract}
O vivente, portanto, não é sem consciência, mas tem uma consciência sem problemas, quer dizer, sem exterioridade, mundo interior cujo centro ele ocupa, consciência que não se preocupa em situar-se em relação a uma exterioridade, que não se capta como parte do todo (pois ela precede todo apreender), consciência sem consciência, à qual corresponde o termo (que não dissimula menos contradições) de inconsciente ou de instinto.
\end{abstract}

Ele estabelece ao "eu" a responsabilidade pelo "Outro", sendo ela, uma responsabilidade pela alteridade do Outro, ou seja, por aquilo que diverge, que constantemente escapa, deixando somente resquícios, aquilo que é definitivamente distinto, não em um sentido qualitativo, mas substantivo (LÉVINAS, 2005). A alteridade surge na vulnerabilidade da exposição do seu rosto, como manifestação 
inaugural que abre o sentido ético, como se destaca a seguir:

A morte do outro homem me concerne e me questiona como se eu me tornasse, por minha eventual indiferença, o cúmplice desta morte invisível ao outro que aí se expõe; e como se, antes de ser eu mesmo voltado a ele, tivesse que responder por esta morte do outro e não deixar outrem só, em sua solidão mortal (LÉVINAS, 1998, p. 194).

Uma vez responsável pelo Outro, torna-se, também, responsável pelas conjunturas em que ele se encontra. "A responsabilidade implica dois compromissos: o primeiro refere-se à resposta pelos próprios atos, e o segundo, pelos atos de outrem; ambos estão relacionados à responsabilidade social" (BARROS, 2009, p. 30). Não há como transferir a responsabilidade gerada pelas escolhas e, também, suas consequências. Ser responsável pelo Outro é, por natureza, inseparável do ser, estar enraizado no interior de cada pessoa, por mais que não haja um conhecimento a seu respeito.

Todavia, a desvalorização do Outro é recorrente na sociedade contemporânea. Pivatto (2005) chegou a considerar que a modernidade levou à "redução do Outro", o que resulta em uma linear "[...] perda de influência da alteridade na experiência existencial e moral, fomentando, assim, a intolerância e a violência" (BARROS, 2009, p. 26). Isso é perceptível quando se encontra a cultura da valorização pessoal e autônoma, que eleva as vontades e os desejos individuais em primeiro lugar e posiciona à parte o interesse comum e, principalmente, a preocupação com o próximo. Segundo Kuiava (2006, p. 56), "sob o ponto de vista filosófico tradicional, a responsabilidade se constitui como decorrente da liberdade", conquanto o mundo exterior causa interferência na liberdade individual. A teoria da liberdade regulada de Silva (1998) defende que o indivíduo possui uma "suposta" liberdade, mas tendo como argumento a ampliação da liberdade e da autonomia, o controle externo é direcionado para o interior de cada pessoa. "Dessa forma, o sujeito não é autônomo e autossuficiente, mas é controlado por meio das relações exteriores" (BARROS, 2009, p. 30).

Diferentemente da visão tradicionalista sobre a responsabilidade, ao proclamar que "[...] somente admitindo que o agente tem certa liberdade de opção e de decisão é que se pode responsabilizá-lo pelos seus atos" (VÁZQUEZ, 2007, p. 109), a filosofia levinasiana defende o "eu" como infinitamente responsável perante o "outro", "a responsabilidade não é uma escolha e sim uma obrigação” (BARROS, 2009, p. 30). Em meio a uma sociedade habituada a uma cultura de valorização de si mesmo e pensamentos individualistas, é necessária a disseminação da alteridade, o que significa a ênfase do Outro na dimensão ética. No contexto da RSU, considera-se que as atribuições das Instituições de Ensino Superior (IES) têm-se modificado com o passar do tempo. As IES que eram tidas como garantidoras da conservação de formas de conhecimento culturalmente reverenciadas, passaram a ser fonte de pessoal altamente qualificado e tornaram-se prestigiadas pelos seus investigadores dedicados a satisfazer necessidades econômicas a agentes do desenvolvimento e da transformação social.

A RSU envolve a constituição da identidade autônoma universitária articulada ao processo democrático e cidadão almejado pela sociedade (SOLIS, 2021). Dessa maneira, é relevante que se criem espaços dialógicos entre universidade e sociedade para seu processo de constituição institucional socialmente 8responsável (EIDT; CALGARO, 2021). A universidade deve-se comprometer com a formação ofertada aos alunos. É um diferencial formar profissionais socialmente responsáveis. Mas, para que isso aconteça, é necessário produzir sensibilização, com o objetivo de que os alunos enxerguem os problemas sociais que os rodeiam, "o movimento que cria o mundo do pensamento é o mesmo que abre o pensamento ao mundo" (MORIN, 2015, p. 77).

Concerne à universidade facilitar $\mathrm{o}$ 
desenvolvimento de seus alunos. No entanto, é essencial constatar que o desenvolvimento não é somente acadêmico e informativo. Constitui-se em produzir condições para que o indivíduo aprenda a pensar por si mesmo e a reconhecer seus ideais e opiniões, de maneira a promover a leitura da realidade do mundo. Nessa linha de pensamento, "[...] a universidade não pode ser indiferente ao seu entorno, à comunidade na qual está inserida e que a interpela, invoca respostas e a convoca a responsabilidade" (BARROS; FREIRE, 2011, p. 894).

A RSU gera o elo necessário entre o conhecimento originado no contexto da sua aplicação, seja ele científico, tecnológico, humanístico e artístico, e as deficiências locais, nacionais e até globais. Para Vallaeys (2006), por via da universidade se molda o mais alto nível de qualificação da pessoa, sob o ponto de vista técnico e científico, profissional e cidadão, comprometido com a mudança almejada pela sociedade. Segundo Goergen (2006), o centro da RSU está no que ela sabe, pode e deve realizar gerando as disposições necessárias para a produção de conhecimentos e saberes, de modo particular no contexto acadêmico brasileiro que é marcado por significativas diferenças regionais. A responsabilidade é uma "[...] palavra que sempre parece ressoar em função de uma esperança, de uma vontade, de uma soberania, daquilo que esperamos do futuro" (PETERSON, 1999, p. 159). Partindo desse princípio, Barros e Freire (2011) entendem que existe uma esperança de transformação social depositada na universidade, o que pressupõe uma responsabilidade intrínseca à sua existência, ao se enxergar incorporada à realidade, "[...] a universidade passa a assumir seu compromisso social, e o estudante começa a compreender sua própria responsabilidade" (BERTO, 2011, p. 25-26).

É fundamental que a universidade proveja a sociedade de recursos humanos qualificados, com capacidade de intervir, de forma real, em suas áreas de atuação, mas também, que providencie explicações e soluções às demandas sociais emergentes, pois "a universidade, como agência social especializada em conhecimento e educação, mais do que qualquer outra, é o espaço apropriado para pensar, discutir e fazer propostas" (JULIATTO, 2004, p. 15). É nesse sentido que Barros (2009) propõe a relação entre a filosofia levinasiana e a RSU, ao considerar a sociedade o Outro da universidade (eu). Nessa linha de pensamento, Barros e Freire (2011, p. 36) argumentam: "A universidade deve responder ao Outro, aqui representado pela sociedade em seu entorno, a partir de uma reflexão sobre o seu significado social, da busca de atendimento às demandas da comunidade, da produção de conhecimentos e da formação de profissionais responsáveis."

A aplicação da responsabilidade social na universidade de modo que responda à invocação que emana da comunidade externa, no sentido levinasiano, deve acontecer de forma diversificada e aliar o ensino à pesquisa e à extensão por meio estratégias e do envolvimento com a comunidade local. A universidade mantém laços com a comunidade, entende seus dilemas e problemas coletivos. Na perspectiva da ética da alteridade radical, a universidade tem a obrigação de responder ao chamado da sociedade (BARROS, 2009, BARROS; FREIRE, 2011). Nessa perspectiva, os projetos socioacadêmicos possibilitam o aperfeiçoamento das competências técnicas e proporcionam o desenvolvimento de valores e princípios direcionados ao desenvolvimento humano. Tais valores e princípios são faróis essenciais para orientar o comportamento humano, conforme afirma Berto (2011, p. 30) ao complementar que "os projetos socioacadêmicos, quando abrangem princípios e valores do plano pessoal, social e universitário, aplicados à gestão responsável, à pesquisa, à docência e à extensão, ultrapassam a filantropia [...]."

A apreensão para com o bem-estar social, especialmente no contexto levinasiano, não assume o lugar do caráter filantrópico e assistencialista de anteriormente. Segundo Berto (2011, p. 24), "as ações de filantropia, motivadas por razões humanitárias, são isoladas e relativas, enquanto o conceito de respon- 
sabilidade social possui uma amplitude muito maior." Atualmente, a universidade deve cooperar com a sociedade por meio de projetos fundamentados em problemas sociais concretos, atuais, que possuam sintonia com a realidade vivenciada, ou seja, "[...] a Responsabilidade Social Universitária exige, a partir de uma visão holística, a articulação das diversas partes da instituição, em um projeto de promoção social de princípios éticos e de desenvolvimento social equitativo e sustentável [...] "(VALLAEYS, 2006, p. 39).

Considera-se a universidade "[...] uma poderosa alavanca para o desenvolvimento cultural, social e econômico da comunidade onde se encontra" (JULIATTO, 2004, p. 18). Pensar nesse contexto, sobre a responsabilidade social universitária, significa refletir sobre as incumbências que estão inerentes à natureza institucional das IES, refletida na transparência e na ética nas suas relações, no respeito à diversidade.

\subsection{O SECRETARIADO EXECUTIVO E A FORMAÇÃO DA CONSCIÊNCIA SOCIAL}

O surgimento dos cursos superiores na área secretarial ocorreu para atender a uma demanda social, advinda de uma categoria profissional e de organizações que necessitavam de profissionais qualificados. Emergiu, assim, uma formação diferenciada e voltada para além do mundo do trabalho, pois a educação é uma prática social, intimamente ligada ao desenvolvimento integral do sujeito, comprometendo-se com a formação da cidadania e seu pleno exercício (BASTOS, 2008, p. 181). Dessa forma, a IES, além da missão de formar profissionais de alto nível nas diversas áreas do conhecimento, tem obrigação de contribuir para formação de opiniões, levar informação àqueles que não têm acesso a ela e gerar consciência acerca da realidade social.

Os projetos de extensão têm sido eficazes ferramentas para se chegar às camadas sociais, proporcionando troca de informações e conhecimentos que engrandecem não apenas as pessoas da comunidade em geral, mas, principalmente, a massa crítica formada dentro da universidade, e esta passa, então, a atuar, de forma mais condizente, com a realidade (CAPELETTE; MAZZEI, 2007). "Ela (extensão) vai desenvolver exatamente aquelas pesquisas que a sociedade está requerendo, vai se preocupar em explorar aqueles problemas que são candentes à sociedade em que ela está inserida" (SAVIANI, 1984, p. 64-65, grifo do autor). Conforme o Plano Nacional de Extensão Universitária, a extensão é, assim como a filosofia, uma ação política, democrática, e indica que a Instituição que a prática é engajada na solução de problemas sociais, utilizando pesquisas básicas e aplicadas, e assim, intervindo diretamente na realidade (BRASIL, 2000). Nesse sentido, a Resolução No 7 , de 18 de dezembro de 2018, que estabelece as Diretrizes para a Extensão na Educação Superior Brasileira afirma que " [...] a interação dialógica da comunidade acadêmica com a sociedade por meio da troca de conhecimentos, da participação e do contato com as questões complexas contemporâneas presentes no contexto social" (BRASIL, 2018, p. 2).

A prática da extensão no ensino superior é muita rica em proporcionar o desenvolvimento do caráter cidadão para os discentes, e, dessa forma, amadurecer ou/e formatar uma consciência social. No entanto, não é o único meio capaz de desenvolver essa consciência. A graduação em si impulsiona o discente em direção ao pensamento crítico, voltado para a realidade, e, assim, evidenciando pensamento coletivo e de responsabilidade para com o Outro. Nesse sentido, a educação superior dispõe de instrumentos geradores de saberes capazes de transformar a realidade (ÁGUILA, 2020). Espera-se que, por meio da tríade ensino, pesquisa e extensão, a universidade cumpra sua função social ao formar cidadãos responsáveis e éticos e responder à sociedade como Outro (BARROS, 2009).

Acredita-se que uma contribuição para a constituição do secretário executivo como profissional e cidadão é a formação da consciência 
social no âmbito universitário. Charles Sanders Peirce, conhecido filósofo americano, deu origem à teoria máxima científica da continuidade, o sinequismo. Na visão de Peirce (1999), o universo existe sob a forma de um conjunto contínuo de todas as suas partes, sem existirem partes totalmente separadas, determinadas ou definida. Esse universo é contínuo em crescimento, complexidade e conectividade, por meio da semiose e do funcionamento de um irredutível e onipresente poder de generalidade relacional, para mediar e unir substratos (ZULIANI, 2011).

De forma prática, "toda comunicação de mente para mente é a continuidade do ser." (PEIRCE, 1999, p. 151). Os pensamentos gerados em mentes individuais interligam-se para participarem de um pensamento social. O sinequismo de Peirce (1999) afirma que consciência carnal é somente uma pequena parte do homem, pois, além desta, há a consciência social, "[...] pelo qual o espírito de um homem é incorporado em outros, e que continua a viver e respirar e a ter o seu ser muito mais do que observadores superficiais imaginam" (PEIRCE, 1999, p. 151). A ideia de uma identidade pessoal é ampliada para incluir uma dimensão social da mente, dessa forma, segundo a visão de Peirce (1999, p. 151), "O sinequista não pode dizer: "eu sou inteiramente eu mesmo e de maneira nenhuma tu." Se abraçares o sinequismo, deves abandonar essa metafísica perversa. Em primeiro lugar, teus vizinhos são, em certa medida, tu mesmo, de maneira muito mais ampla."

Vygotsky (2004), ao tentar explicar o conceito de consciência, relaciona-o à vida, já que o sujeito, por meio da consciência, projeta aquilo que irá construir na natureza, diferente dos demais animais, que o fazem por instinto. Freire (1980) enfatiza que o produto final da consciência deve ser a conscientização. A formação de uma conscientização é diretamente proporcional à condição de que essa consciência esteja vinculada a uma atividade. Ele dá ênfase ao fragmento final da palavra, "ação", dessa forma, as atitudes deveriam estar vinculadas ao discurso, o que demonstra um compro- metimento ético do sujeito e gera maior nível de conscientização. Conforme a filosofia de Peirce (1999), percebe-se que o pensamento, o sentimento e a existência estão espraiados pelo universo, ou seja, nada é antropocêntrico (ZULIANI, 2011). Pape (1997) associa o conceito da continuidade presente no sinequismo, com o "Amor Agápico". O amor agápico permeia tudo e todos e confere à sociedade um progresso cultural que é viável apenas em meio a um conjunto de seres, colocando seus sentimentos a serviço da organização do mundo. Sobre esse aspecto ressalta-se:

Agapismo é a evolução por meio do amor criativo, a lei do amor, uma liberdade fundamental que é o sopro do espírito de amor. Uma ontologia agápica, então, seria uma ontologia que permite a ação teleológica, a ação como aquela engendrada pelo amor que surge entre as pessoas que não escolhem, mas são postas em movimento por ele (ZULIANI, 2011, p. 47).

O termo "agápico" remete à religião; entretanto, Peirce (1999) não considerou o sinequismo uma religião, ou uma forma de explicá-la, pelo contrário; para ele, o sinequismo é uma filosofia puramente científica, passível de explicação, podendo exercer "[...] um importante papel na reconciliação entre religião e ciência" (PEIRCE, 1999, p. 152). Portanto, a consciência social, na visão de Peirce (1999), é formada por meio da continuidade do ser, pois este não termina em si, mas continua no Outro.

A extensão, por meio de ações de contato com a comunidade externa, é a dimensão universitária que mais se move nesse sentido da RSU. No contexto do Secretariado Executivo, a prática da RSU tem potencial para promover uma formação cidadã, isso influencia no desenvolvimento da consciência social do indivíduo, despertando-o para refletir sobre o impacto das suas ações no Outro. Essa consciência, adquirida na graduação, permanece no profissional. E como é passível de realizar notável diferença, um profissional de Secretariado Executivo hu- 
mano, é capaz de exercer empatia, solidariedade e respeito para com o próximo, em seu ambiente de trabalho, já que este, constantemente, necessita lidar com uma variedade de públicos dentro e fora da empresa.

\section{METODOLOGIA DA PESQUISA}

Esta pesquisa se insere no modelo qualitativo, realizada por meio de levantamento bibliográfico e estudo de campo. O universo foi composto por quatro discentes do curso de Secretariado Executivo da Universidade Federal do Ceará. A seleção dos participantes considerou os seguintes critérios: ser aluno do curso de Secretariado Executivo da Universidade Federal do Ceará, ter participado ou estar participando de uma ou mais ações de responsabilidade social vinculadas ao curso de Secretariado Executivo da Universidade, ter participado ou estar participando de atividades de pesquisa e extensão e aceitar participar da pesquisa.

A quantidade de participantes definida se justifica pela necessidade de aprofundamento da análise, considerada como um "processo que conduz à explicitação da compreensão do fenômeno pelo pesquisador" (SZYMANSKI; ALMEIDA; BRANDINI, 2004, p. 65). Trata-se, portanto, de um processo amplo e profundo de coleta, reflexão e análise de informações que inviabiliza um quantitativo amplo de participantes. Com o intuito de manter em sigilo as identidades dos entrevistados, os participantes foram identificados como: Entrevistado 1, Entrevistado 2, Entrevistado 3 e Entrevistado 4.

Recorreu-se à técnica de entrevista reflexiva, método que torna horizontais as relações de poder, considera a participação dos atores envolvidos, incluindo suas subjetividades no processo de interação social, igualmente (SZYMANSKI; ALMEIDA; BRANDINI, 2004). Como instrumento de coleta de dados, foram utilizados um roteiro com uma pergunta norteadora, sete focalizadoras, e cinco de aprofundamento. Szymanski, Almeida e Brandini (2004) apontam a necessidade de a entrevista acontecer em, no mínimo, dois encontros. Para o desenvolvimento desta pesquisa, houve três encontros individuais.

O convite inicial para participar da pesquisa foi feito por telefone. Após o aceite, foi agendado o primeiro encontro em que foram apresentados a pesquisa e os objetivos, bem como a descrição de como ocorreria a sua participação. No segundo momento, foi esclarecido para os entrevistados o significado dos termos Responsabilidade Social e Consciência Social, para os objetivos da investigação, conforme os principais teóricos que a fundamentam, seguida da entrevista, registrada por meio de um gravador de voz. Para o segundo momento, foi elaborado um roteiro contemplando os tópicos necessários para a pesquisa.

A terceira fase aconteceu após escuta dos áudios das entrevistas. Foram pautados os assuntos que precisavam ser abordados novamente e/ou aprofundados. Todos os encontros aconteceram na Universidade, em uma sala previamente reservada.

A pesquisa reflexiva propõe que o entrevistador compartilhe sua compreensão com o participante, mediante uma devolutiva a fim de possibilitar uma interação perceptual do Outro e de si e vislumbra-se uma participação ativa de ambos no resultado final (SZYMANSKI; ALMEIDA; BRANDINI, 2004). A devolutiva foi realizada após a construção da apresentação e análise de dados enviada por correio eletrônico aos participantes da pesquisa. Os entrevistados não apontaram para a necessidade de exclusão ou de modificação de algum depoimento, mas reafirmaram sobre como a pesquisa pode trazer muitas reflexões a respeito da sua atuação no âmbito do curso.

A análise dos dados seguiu as etapas propostas por Szymanski, Almeida e Brandini (2004): (1) transcrição e leitura integral dos depoimentos para se familiarizar com o texto; (2) separação das unidades de significado, das respostas para seus questionamentos consideradas relevantes para esta pesquisa; (3) transformar as expressões cotidianas apresentadas pelos entrevistados em linguagem psicológica, de modo a atribuir significados, e (4) sintetização de todas as unidades de significado e elaboração de uma síntese para cada depoimento. 


\section{APRESENTAÇÃO E ANÁLISE DOS DADOS}

A pesquisa teve como enfoque manifestações de responsabilidade social que envolvem ensino, pesquisa e extensão. Na percepção dos discentes participantes, encontram-se pontos convergentes e divergentes em relação ao tema. O quadro 1 apresenta os principais depoimentos e a explicitação de significado.

Quadro 1 - Categoria: Responsabilidade Social no ensino

\begin{tabular}{|l|l|}
\hline \multicolumn{1}{|c|}{ Depoimentos } & \multicolumn{1}{|c|}{ Explicitação de significado } \\
\hline $\begin{array}{l}\text { "Em alguns discursos dos professores sobre o assunto } \\
\text { existe, mas nada que seja incentivado de forma objetiva" } \\
\text { (ENTREVISTADO 1). }\end{array}$ & $\begin{array}{l}\text {-Identifica a presença de fundamentos } \\
\text { da Responsabilidade Social na fala dos } \\
\text { professores em sala de aula. } \\
\text { - Porém, não percebe esse conhecimento } \\
\text { como objetivo acadêmico. }\end{array}$ \\
\hline $\begin{array}{l}\text { "Além de conversar sobre o que é responsabilidade social } \\
\text { e consciência social, eu acho que tem que entender, porque } \\
\text { podemos até tocar no assunto durante as aulas, mas não é } \\
\text { possível entender o que de fato é isso" (ENTREVISTADO 3). }\end{array}$ & $\begin{array}{l}\text {-Estudo de teóricos da área. } \\
\text { senso comum. }\end{array}$ \\
\hline $\begin{array}{l}\text { "Acho que disciplinas voltadas mais para questão qualitativa a necessidade de sair do } \\
\text { são as que ainda contribuem para esse pensamento para esse } \\
\text { fenômeno assim da responsabilidade social, de consciência } \\
\text { dentro da turma" (ENTREVISTADO 4). }\end{array}$ & $\begin{array}{l}\text {-Percebe o tema responsabilidade social } \\
\text { nas disciplinas com abordagem qualitativa. }\end{array}$ \\
\hline
\end{tabular}

Fonte: dados da pesquisa (2019).

O Entrevistado 1 identificou que existe o debate sobre o tema na fala dos professores em sala de aula; entretanto, caracterizou a transmissão desse conhecimento como uma "fala pessoal dos professores", não sendo normalmente relacionado com a profissão. A temática não seria um ponto forte no ensino. O conhecimento constituído pelos professores implica um exercício da própria responsabilidade para com o Outro. Conforme Lévinas (2005), deve-se "responder não só pelo Rosto do outro homem", mas formar "um terceiro", isso seria viver em sociedade, pensar no todo. Essa relação para com o Outro, segundo Lévinas (1980), ultrapassa o exercício da simpatia, constitui uma obrigação, que, no caso, o professor teria em demonstrar a "alteridade", ao expor a realidade aos alunos. Os alunos, por sua vez, passam a assumir uma obrigação de replicar o que aprendem para a sociedade. O Entrevistado 4 afirmou: "No ensino do Secretariado Executivo, poucas disciplinas tratam sobre responsabilidade social. Como a gente estuda gestão, as disciplinas principalmente cálculo, disciplinas quantitativas, são bem mais específicas e mais diretas, mais rígidas [...]."
O Entrevistado 3 ressaltou a necessidade de estudar o tema de forma aprofundada e observar os teóricos da área, com o intuito de sair do senso comum e adentrar na ciência. Essa visão dialoga com as ideias de Berto (2011), ao ponderar que o conceito de responsabilidade social possui uma amplitude maior que as práticas assistencialistas e sociais, sendo necessário, portanto, um olhar aprofundado para o tema.

A análise das respostas obtidas à luz da teoria revela que, no contexto do ensino, ainda há necessidade de se estudar temas de responsabilidade social nas disciplinas, de maneira intencional, planejada e inserida nos conteúdos propostos. Sem desvalorizar a influência da postura de professores em relação à importância da responsabilidade e da consciência social, denota-se que os estudos acerca do tema nas disciplinas, precisam ser fundamentados na ciência e não somente nos posicionamentos dos docentes. Acredita-se que, para tanto, faz-se necessário trabalhar o tema de forma transversal, com base no plano de ensino.

Sobre a Responsabilidade Social no âmbito da pesquisa, são apresentadas as principais considerações no quadro 2 . 
Quadro 2 - Categoria: Responsabilidade Social na pesquisa

\begin{tabular}{|l|l|}
\hline \multicolumn{1}{|c|}{ Depoimentos } & \multicolumn{1}{|c|}{ Explicitação de significado } \\
\hline $\begin{array}{l}\text { "Com pesquisa a gente consegue enxergar algumas } \\
\text { dificuldades que existem em relação à universidade } \\
\text { pública, ou o que nós estamos enfrentando hoje" } \\
\text { (ENTREVISTADO 2). }\end{array}$ & $\begin{array}{l}\text {-A pesquisa tem potencial para expor a } \\
\text { realidade social }\end{array}$ \\
\hline $\begin{array}{l}\text { "Dentro da pesquisa eu acredito que o fato de fazer visita de } \\
\text { campo para públicos que não tinha tanto acesso contribuiu } \\
\text { muito com essa visão social" (ENTREVISTADO 3). }\end{array}$ & $\begin{array}{l}\text {-A prática da pesquisa de campo gera no } \\
\text { pesquisador um olhar social. }\end{array}$ \\
\hline $\begin{array}{l}\text { "A pesquisa, eu acho que eu não vejo tantos resultados, } \\
\text { claro, a gente vai deixar aí as conclusões da pesquisa que } \\
\text { podem ser e aquele se tornou ciência, mas eu sempre } \\
\text { gostei de uma coisa mais prática" (ENTREVISTADO 4). }\end{array}$ & $\begin{array}{l}\text {-O resultado da pesquisa pode ser usado para } \\
\text { o desenvolvimento de ações sociais. }\end{array}$ \\
temática no curso. \\
\hline
\end{tabular}

Fonte: dados da pesquisa (2019).

A participação em grupo de pesquisa foi apontada como lócus da prática de investigação científica, apesar de existirem disciplinas em que é cobrada essa produção. Nesse sentido, os Entrevistados 1, 2 e 3 ressaltaram o potencial da pesquisa em expor a realidade social, observando que a prática da pesquisa de campo pode gerar no pesquisador um olhar mais humanístico. Esse processo pode ser analisado à luz do pensamento de Morin (2015), que considera a pesquisa como o movimento que cria uma reflexão e faz, dessa reflexão, um movimento.

O Entrevistado 3 afirmou: "[...] quando a gente vai fazer uma pesquisa, a gente tem que estudar as pessoas, e não só estudar, mas ouvir, conhecer a realidade dessas pessoas, e, se possível, produzir uma intervenção". Essa percepção corrobora o pensamento de Juliatto (2004) ao caracterizar a universidade como uma agência social especializada em conhecimento e educação e, portanto, como espaço apropriado para pensar, discutir e fazer propostas. Lévinas (2005) discute como o conhecimento do mundo exterior causa interferência na liberdade individual, pois revela a condição em que o Outro se encontra, e como responsável por ele, o "eu" precisa agir.

Apesar de admitir o potencial dos resultados da pesquisa como ponto de partida para intervenções sociais, o Entrevistado 4, considerou que existe, no Curso, manifesta- ções mais práticas sobre a temática, apontando para as ações de extensão: “[...] eu sempre gostei de uma coisa mais prática, realmente colocar a mão na massa, então eu acredito que a extensão seja o que mais colabora" (ENTREVISTADO 4). Tal resposta dialoga com Capelette e Mazzei (2007), para quem os projetos de extensão são as ferramentas mais eficazes para se chegar às camadas sociais por permitir contato com o Outro. Nesse sentido, evoca-se Peirce (1999) ao afirmar que essa relação, e o impacto no Outro constitui importante ponto para pensar a consciência social.

Os dados apresentados, em cruzamento com a teoria estudada, denotam que os participantes reconhecem a pesquisa como uma forma de se perceber a realidade social, o que pode desenvolver a capacidade de reflexões críticas e, consequentemente, um movimento direcionado à transformação social. Observa-se, porém, que, no âmbito da pesquisa, a manifestação da Responsabilidade Social é percebida pelos alunos quando se desenvolve pesquisa de campo. Revela-se a necessidade de melhor compreensão acerca da função social e da práxis da investigação científica.

No que se refere à responsabilidade social por meio de ações extensionistas, o quadro 3 reflete o pensamento dos entrevistados sobre o tema. 
Quadro 3 - Categoria: Responsabilidade Social na extensão universitária

\begin{tabular}{|l|l|}
\hline \multicolumn{1}{|c|}{ Depoimentos } & \multicolumn{1}{|c|}{ Explicitação de significado } \\
\hline “[...] eu vi muito essa necessidade de ajudar & -Desenvolvimento da empatia. \\
as pessoas, ajudar os alunos que passam de & -Projeto impacta a própria comunidade interna do \\
momentos específicos dentro da graduação" & curso. \\
(ENTREVISTADO2). & \\
\hline "Eu vejo que tem muitas vantagens de criar & -Aponta benefícios no envolvimento com projetos \\
projetos e impactar os mais diversos públicos" & de extensão. \\
(ENTREVISTADO3). & \\
\hline "[...] eu pude ver muito a questão da valorização & - A comunidade que recebe o projeto de extensão \\
e do entusiasmo da comunidade em receber o o \\
curso que estava sendo ministrado, eles estavam \\
valorizando algo que a gente estava ensinando, \\
e pude absorver disso, por exemplo, uma certa \\
empatia com a comunidade e de certa forma com o \\
mediante o comportamento no projeto é impactado \\
Curso, uma valorização mútua com o que é aquele \\
projeto" (ENTREVISTADO 4).
\end{tabular}

Fonte: dados da pesquisa (2019).

O Entrevistado 3 observou que existe a geração de benefícios com base no envolvimento em projetos de extensão. O entrelaçamento entre discente e Universidade, em todo os seus aspectos, permite, conforme Juliatto (2004), o desenvolvimento de uma alavanca que proporciona desenvolvimento cultural, social e econômico, de maneira recíproca. $\mathrm{O}$ Entrevistado 4 ponderou, em seu depoimento, sentir a valorização por parte da comunidade que o recebe por meio de um projeto de extensão direcionado à formação profissional do qual participou, pois se torna um divisor de águas para a reinserção de alguns no mercado de trabalho, e para outros um momento de socialização. Poder observar esse impacto gerado na vida das pessoas despertou no entrevistado apreciação para com o projeto e empatia para com a comunidade externa. Berto (2011) reitera que esse envolvimento de assumir um compromisso social junto a universidade gera no estudante a compreensão da sua própria responsabilidade.

O Entrevistado 2 manifestou que, desde a sua participação em projeto de extensão, desenvolveu sentimento de empatia, por impactar a comunidade. Acrescentou que se posicionou como agente promotor de motivação para com discentes e classificou a motivação como fator importante na graduação visto que oportuniza "[...] gerar comportamento positivo ou negativo dentro do Curso" (ENTREVISTADO 2). Nesse sentido, relembramos o que Lévinas (2005) afirmou sobre a responsabilidade manifestada em dois compromissos, sendo o primeiro referente à resposta pelos próprios atos e, o segundo, pelos atos de outrem. Vale ressaltar que, na perspectiva levinasiana, a empatia não é suficiente para a responsabilidade, mas se faz necessário o reconhecimento da total alteridade do Outro.

Infere-se que a atividade extensionista apresenta-se como o principal eixo norteador para a constituição da responsabilidade e da consciência social. As ações de extensão, na percepção dos participantes, apresentam maior manifestação da responsabilidade social, visto que possibilitam contato direto com a comunidade externa.

Ao serem questionados sobre como a Universidade, mais especificamente, o curso de Secretariado Executivo, seria capaz de desenvolver a consciência social no indivíduo, foi apontado o fator da diversidade como desencadeador, conforme se observa no quadro 4. 
Quadro 4-Categoria: A Universidade e a diversidade

\begin{tabular}{|c|c|}
\hline Depoimentos & Explicitação de significado \\
\hline $\begin{array}{l}\text { "Acho que, por ela ter essa questão de ter acesso a } \\
\text { uma diversidade [...], traz uma abrangência maior } \\
\text { para essas questões, cada pessoa vai vivendo a } \\
\text { Universidade de certa forma, e ela vai despertando } \\
\text { o interesse, assim como eu tive interesse } \\
\text { nas questões voltadas para a diversidade ações } \\
\text { afirmativas" (ENTREVISTADO 1). }\end{array}$ & $\begin{array}{l}\text {-A Universidade facilita a manifestação da } \\
\text { diversidade, assim como promove o debate sobre } \\
\text { o tema. } \\
\text {-A realidade da universidade tem potencial } \\
\text { para despertar interesses dos indivíduos para a } \\
\text { diversidade e gerar ações nesse sentido. }\end{array}$ \\
\hline $\begin{array}{l}\text { "Eu cheguei à universidade logo no primeiro } \\
\text { semestre entrei no CA, e eu tive que trabalhar com } \\
\text { pessoas de distintas personalidades e qualidades, } \\
\text { tive que perceber característica nas pessoas } \\
\text { e meio que canaliza isso para um objetivo e } \\
\text { obter consciência sobre o meu papel social } \\
\text { naquele ambiente, respeitando as diferenças" } \\
\text { (ENTREVISTADO 2). }\end{array}$ & $\begin{array}{l}\text {-Ambiente propício para se trabalhar com } \\
\text { diferenças e desenvolver respeito. }\end{array}$ \\
\hline $\begin{array}{l}\text { "Eu acredito que a universidade tem um papel muito } \\
\text { importante no próprio significado de Universidade, } \\
\text { que é unir as diversidades, e eu acho que quando } \\
\text { você pensa em pessoas diferentes você tem que ter } \\
\text { uma responsabilidade por trás disso, porque nem } \\
\text { todo mundo pensa igual, e, para existir consciência } \\
\text { social, tem que existir uma empatia muito grande e } \\
\text { muito respeito" (ENTREVISTADO 3). }\end{array}$ & $\begin{array}{l}\text {-Significado do nome universidade se manifesta } \\
\text { em seus resultados, sendo local que promove a } \\
\text { união das diversidades. } \\
\text { - Estar em um ambiente fértil para a diversidade } \\
\text { gera no indivíduo o sentimento de empatia e } \\
\text { respeito. } \\
\text { - A empatia e o respeito são fundamentais para o } \\
\text { desenvolvimento da consciência social. }\end{array}$ \\
\hline
\end{tabular}

Fonte: dados da pesquisa (2019).

O Entrevistado 3 ressaltou o próprio significado do termo Universidade: unir as diversidades. Segundo o Entrevistado 1 a Universidade não só facilita a manifestação da diversidade, mas promove um contínuo debate sobre o tema, de modo que os diferentes encontram espaço para crescer. Este ambiente fértil para a diversidade teria potencial de gerar no discente, segundo o Entrevistado 3, o sentimento de empatia e respeito, estes, por sua vez, são fundamentais para o desenvolvimento de uma consciência social. Portanto, a realidade da Universidade tem competência para direcionar o olhar dos indivíduos para a diferença e gerar ações no sentido de saída de si mesmo em direção ao Outro (LÉVINAS, 2005). O Entrevistado 1 complementou que o curso permite que você tenha contato com,

[...] diversas pessoas, diversos ambientes e você começa a perceber coisas que você não tinha percebido, e a pensar fora da caixa. Eu acho que é necessário até para o profissional de Secretariado, porque ele precisa estar constantemente se desenvolvendo, se inovando, e é sempre bom está aberto à diversidade e às diferenças que existem, entrar em causas sociais para lutar ter um engajamento social (ENTREVISTADO 1).

Acredita-se que, mediante o discernimento do mundo exterior, é possível a conexão do homem com os outros homens (BARROS, 2009). O homem não é um ser autônomo, mas é controlado por meio das relações exteriores, porque, a partir delas, formam-se comportamentos, pensamentos e práticas (LÉVINAS, 2005). Se não houvesse esse estabelecimento de relação com o exterior, também não haveria a formação dessas ações. O discurso do Entrevistado 1 sugere que o contato com a realidade do diferente não o constitui apenas como es- 
tudante, mas também como futuro profissional, o que sugere a ideia da necessidade contínua de relacionamento com o mundo exterior.

Compreende-se que o envolvimento do estudante com as atividades investigativas oportuniza a constituição da consciência social, por meio de um olhar para o Outro e o seu lugar na sociedade. O desenvolvimento da responsabilidade social levinasiana ocorre por meio do envolvimento com ações sociais e desperta sentimentos de empatia e acolhida à diversidade, à alteridade.

Acerca da relação da Universidade com o Outro, apresentam-se as principais considerações no quadro 5.

Quadro 5 - Categoria:A Universidade e o Outro

\begin{tabular}{|c|c|}
\hline Depoimentos & Explicitação de significado \\
\hline $\begin{array}{l}\text { "[...] eu ter que precisar sair [da minha realidade] para } \\
\text { enxergar de forma diferente, eu começo a enxergar mil } \\
\text { coisas que poderiam melhorar" (ENTREVISTADO 1). }\end{array}$ & $\begin{array}{l}\text { - Retirada da zona de conforto. } \\
\text { - Confronto com a realidade. } \\
\text { - Desejo por mudanças. }\end{array}$ \\
\hline $\begin{array}{l}\text { "Uma coisa forte que eu pude aprender dentro desses } \\
\text { projetos, que foi essa questão da responsabilidade das } \\
\text { minhas atitudes em relação com relação ao Outro" } \\
\text { (ENTREVISTADO 2). }\end{array}$ & $\begin{array}{l}\text { - Os projetos permitiram ao discente } \\
\text { desenvolver senso de responsabilidade com as } \\
\text { ações que atingem outras pessoas. } \\
\text {-Preocupação com as ações em relação aos } \\
\text { outros. }\end{array}$ \\
\hline $\begin{array}{l}\text { "[...] acho que está tão próximo esse intuito de querer } \\
\text { ajudar pessoas, de querer criar algo, se aproximar } \\
\text { de pessoas diferentes, é mais forte nesse curso" } \\
\text { (ENTREVISTADO 3). }\end{array}$ & $\begin{array}{l}\text {-Enxerga formação de laços dentro da } \\
\text { comunidade acadêmica do curso. }\end{array}$ \\
\hline $\begin{array}{l}\text { "[...] e no decorrer de todas essas atividades, se vocêtirar } \\
\text { um pouco do seu tempo para se envolver em alguma, } \\
\text { eu acho que você vai desenvolver essa consciência } \\
\text { social, você vai desenvolver a empatia com o colega e } \\
\text { a sociedade que está ao redor" (ENTREVISTADO 4). }\end{array}$ & $\begin{array}{l}\text {-O envolvimento dos discentes com as } \\
\text { atividades promovidas pela universidade gera } \\
\text { consciência social. }\end{array}$ \\
\hline
\end{tabular}

Fonte: dados da pesquisa (2019).

O Entrevistado 2 ponderou que o seu engajamento nos projetos de extensão permitiu o desenvolvimento do senso de responsabilidade com as suas ações que beneficiam outras pessoas. O Entrevistado 1 discursou sobre como esses projetos lhe permitiram sair da sua realidade e contemplar realidades diversas, de modo a possibilitar questionamentos e ânsia por mudanças. Observa-se, nessas considerações, movimentos da ideia da exterioridade que, conforme Lévinas (2005), estabelece ao "eu" a responsabilidade pelo "Outro", por meio da saída de si em direção ao diferente. O contato com pessoas, lugares e realidades diferentes ocorre mediante a participação em projetos de extensão. O Entrevistado 4 afirmou que, conforme a sua experiência na Universidade, "a extensão desenvolve mais a consciência social do que o próprio ensino", por promover um contato maior com a sociedade. Os projetos de extensão emergem como um mecanismo ápice no desenvolvimento da consciência social. O Entrevistado 1 contou sobre a sua experiência atuando no projeto de extensão, onde ministrou aula para a comunidade externa:

Tive que dar aula eu fui para o meio do Maracanaú [...] aí você tem uma visão diferente sabe, querendo ou não traz um impacto, não são tão particulares as realidades, dá um estalo e você começa a pensar e se perguntar porque certas coisas acontecem e não deveriam acontecer, você começa a pensar porque que existe tanta desigualdade e coisas do tipo [...]. 
Podem-se associar essas ideias à proposição de Lévinas (2005) no que se refere à exterioridade. A partir do momento em que o indivíduo tem contato com a realidade do Outro uma consciência diferente é gerada, conforme destacou o Entrevistado 1: "[...] essa autopercepção da realidade foi uma mudança muito relevante em mim". O Entrevistado 2 afirmou que os projetos de extensão constituem um ambiente propício para se trabalhar com as diferenças e desenvolver visão crítica acerca da sociedade, que pode culminar em uma consciência social por permitir o contato com o mundo exterior ao indivíduo: "então a universidade forma pessoas além de profissão, ela forma a personalidade, ela forma as suas formas de enxergar o mundo" (ENTREVISTADO 3). A identidade pessoal é ampliada e adquire uma dimensão social da mente, conforme Peirce (1999).

Outro ponto observado pelo Entrevistado 3 concerne às relações geradas no Curso: "Aqui no Secretariado eu sinto que a gente é muito próxima da Coordenação e dos professores, sinto que a gente é meio que uma família, eu não sinto muito essa questão da hierarquia [...]". Percebe-se a formação de laços na comunidade acadêmica interna, e isso gera um sentimento de pertencimento, respeito, e valorização do Outro. A relação aluno-professor, bem como a relação aluno-comunidade, assemelha-se em seus processos de construção e resulta no desenvolvimento de uma consciência social, porque admitem o impacto do outro no ser. Peirce (1999) considera como sinequismo a forma como uma pessoa se propaga na comunidade, porque exerce influência e impacto em outras.

Mesmo com a realização de diversas ações extensionistas e a participação dos estudantes em projetos desenvolvidos no âmbito do curso de Secretariado Executivo, os entrevistados demonstraram sentimento de inquietação em relação à maior participação da comunidade externa no âmbito da Universidade. De forma mais específica no ambiente externo na qual a Universidade está inserida. Tal pensamento corrobora as ideias de Barros e Freire (2011), ao reputarem que a Universidade não pode ser indiferente ao seu entorno, sendo a sociedade o Outro levinasiano da universidade, e que clama por respostas às suas demandas.

Analisa-se que a vida universitária possibilita ao aluno oportunidades de contato com o Outro, na comunidade acadêmica e no extramuros da Universidade. A relação com o exterior promove uma ampliação do olhar acerca da sociedade. Ao conhecer realidades diversas e distintas da sua, o estudante desenvolve a humanidade e a capacidade de acolher o Outro em sua total alteridade e, consequentemente, a consciência social.

O quadro 6 expõe as principais falas dos participantes acerca dessa questão.

Quadro 6-Categoria: Impactos à comunidade externa

\begin{tabular}{|c|c|}
\hline Depoimentos & Explicitação de significados \\
\hline $\begin{array}{l}\text { "A Universidade faz parte de um meio, então ela tem } \\
\text { que conceder retorno para esse meio, afinal ela recebe } \\
\text { recursos desse meio [...] tudo o que começa a mudar na } \\
\text { Universidade começa a partir dela partindo do centro dela" } \\
\text { (ENTREVISTADO 1). }\end{array}$ & $\begin{array}{l}\text {-Universidade recebe recursos da sociedade } \\
\text { e tem obrigação de oferecer retorno. }\end{array}$ \\
\hline $\begin{array}{l}\text { "Estamos localizados no Campus do Benfica, aqui na } \\
\text { Marechal Deodoro, com Centro de Humanas do lado e } \\
\text { o que que a gente faz com a população ao redor das ruas? } \\
\text { Entendeu? Eu estou tendo a visão de assistencialismo? Não } \\
\text { sei, mas não para de pensar sobre o que a gente realmente faz } \\
\text { para as pessoas que estão em volta?" (ENTREVISTADO 4). }\end{array}$ & $\begin{array}{l}\text {-O curso impacta as pessoas vinculadas a } \\
\text { ele } \\
\text {-Necessidade de impactar pessoas do } \\
\text { entorno da Universidade }\end{array}$ \\
\hline $\begin{array}{l}\text { "Às vezes eu me assustava muito porque eu me perguntava: } \\
\text { nossa, mas eu só fico aqui dentro, a gente só faz aqui dentro, } \\
\text { e cadê a comunidade inserida dentro da Universidade?" } \\
\text { (ENTREVISTADO } 3 \text { ). }\end{array}$ & $\begin{array}{l}\text { - Sentimento de inquietação e desejo de } \\
\text { maior participação da comunidade externa } \\
\text { no âmbito da universidade. }\end{array}$ \\
\hline
\end{tabular}

Fonte: sados da pesquisa (2019). 
O Entrevistado 4 indagou: "Eu estou há 4 anos na universidade, será mesmo que eu realmente impactei as pessoas sabe? [...] talvez eu tenha trabalhado muito com as pessoas aqui dentro e não trabalhado com as pessoas lá fora". O Entrevistado 3 acrescentou:

[...] essas pessoas também pertencem à Universidade, e, às vezes, eu fico um pouco frustrada, angustiada e alguém pergunta se a gente, cadê o pessoal de fora? Só tem um pessoal daqui eu acho que é isso, essa Responsabilidade Social mesmo de querer alcançar o máximo possível de pessoas. Eu acho que esse é o intuito fundamental dos projetos que a gente desenrola sempre, como os professores falam em aberto ao público aberto à comunidade.

O Entrevistado 1 demonstra esse questionamento ao ressaltar a importância de se oferecer um retorno à comunidade e pondera que a universidade pública recebe recursos da sociedade e tem o dever de retribuir de alguma maneira, não apenas na formação de profissionais, mas no sentido de gerar envolvimento dos alunos com a sociedade.

Os discursos dos participantes revelam preocupação com o Outro, materializada no olhar dos discentes para com a comunidade externa. Lévinas (2005) argumenta que toda a condição do Outro é responsabilidade do eu, e a indiferença do eu para com o Outro o torna cúmplice da sua situação. O sentimento passado pelos discentes nessas últimas afirmações se assemelha ao pensamento de Lévinas (2005), pois se questionaram sobre assumir responsabilidade para com o meio em que estão inseridos, e manifestaram incômodo para com a inércia em relação ao Outro. O olhar de preocupação e a reflexão humanística sobre o Outro, podem ser apontadas como a fatídica consequência do que a graduação, em toda a sua estrutura, traz para a formação da consciência social do indivíduo, tal corrobora a ideia de Bastos (2008) que estabelece uma relação entre a educação e o desenvolvimento integral do sujeito. Para Freire (1980), o produto final da consciência deve ser a conscientização. Nessa linha de pensamento, Peirce (1999) salienta a necessidade de uma conscientização sobre a importância do Outro, considerando-o até certa medida eu mesmo e o desenvolvimento do "Amor Agápico", o qual situa seus sentimentos a serviço da organização do mundo e ultrapassando a questão religiosa, pois essa atitude encontra explicação nas condições fundamentais para se viver em sociedade. Lévinas (2005) aborda a importância de se exercer uma responsabilidade ética perante o Outro e que a indiferença à condição do semelhante é a fonte de toda inumanidade, e imoralidade.

Diante das reflexões ora desenvolvidas, apreende-se que a realização de atividades de Responsabilidade Social Universitária, fundamentada no pensamento levinasiano voltado para a constituição de uma consciência social, necessita inserir-se na integração entre ensino, pesquisa e extensão.

\section{CONSIDERAÇÕES FINAIS}

A realização desta pesquisa permitiu o desenvolvimento de algumas reflexões conclusivas. Discutiram-se aspectos de Responsabilidade Social que envolvem a tríade ensino, pesquisa e extensão no curso de Secretariado Executivo, sob o olhar de representantes discentes. Evidenciou-se lacuna no estudo acerca do tema como ciência, embora haja a percepção de que os docentes influenciam os alunos a participarem de ações de responsabilidade social, bem como projetam um comportamento socialmente responsável. No âmbito da pesquisa, a manifestação da Responsabilidade Social é mais presente no momento em que existe pesquisa de campo. Considera-se que o objetivo, o desenvolvimento, e/ou conclusão da pesquisa podem proporcionar reflexão sobre práticas socialmente responsáveis. Percebeu-se a maior manifestação da responsabilidade social nas ações de extensão, por promover um contato direto com a comunidade. 
A pesquisa denotou que existe desenvolvimento do senso social nos indivíduos que colaboraram com a investigação. A vivência do discente no ambiente da Universidade possibilita ampliar a visão acerca de quem é o Outro e sobre o significado de viver em sociedade. Sentimentos como empatia e respeito à diversidade foram evidenciados como consequência do envolvimento em ações de Responsabilidade Social.

A graduação proporciona uma série de envolvimento com o Outro, tanto no âmbito interno, como externo, o qual possibilita uma percepção ampliada sobre a sociedade e como o indivíduo exerce certa influência no meio em que se insere. Em outras palavras, o discente adquire contato com realidades diferentes da sua e desenvolve no formando um olhar humano diante da acolhida à diferença, em uma perspectiva levinasiana, favorecendo o desenvolvimento da consciência social.

Pode-se refletir, portanto, que as contribuições da participação em ações de Responsabilidade Social Universitária, em uma perspectiva de valorização do Outro, para a formação da consciência social do aluno, estão vinculadas à concretização da tríade do ensino, pesquisa e extensão de forma integrada. Nesse espaço, ocorre a formação social, bem como, as relações interpessoais que se projetam no âmbito interno e externo ao Curso. Considera-se a relevância do ambiente da Universidade por meio, principalmente, da extensão, por proporcionar intenso envolvimento do ser com o seu meio e criar espaços para se pensar, questionar e ousar responder a certas incógnitas que impactam a formação da consciência social de futuros profissionais. As reflexões ora desenvolvidas apontam para a necessidade de se discutir a temática sob o prisma da abertura ao Outro. Com efeito, emergem novas inquietações acerca da necessidade de ampliar o alcance da Universidade às esferas extramuros. Embora existam movimentos nessa direção, ainda há muito a ser feito para que se ofereçam respostas às demandas da comunidade em seu entorno e possibilitem a concretização de uma sociedade mais justa e igualitária por meio da compreensão da sociedade enquanto Outro da Universidade.

Como limitações desta pesquisa, aponta-se a margem de tempo para a sua realização. Um tempo maior possibilitaria ampliação de encontros com os entrevistados, bem como um amadurecimento das reflexões sobre o tema, tanto por parte dos participantes e das pesquisadoras, como para a condução e direcionamento das entrevistas e análises. Para pesquisas futuras, sugere-se refazer o mesmo questionamento a um grupo distinto de estudantes e incluir outros cursos da Universidade e representantes docentes e técnico-administrativos com o intuito de ampliar o olhar sobre o objeto de estudo.

\section{REFERÊNCIAS}

ÁGUILA, M. A.F. Empatía y respeto entre otros valores: análisis de experiencias docentes de colaboración con organizaciones sociales. Rev. Digit. Invest. Docencia Univ., Lima, v. 14, n. 1, 2020. Disponível em: http://www. scielo.org.pe/scielo.php?script $=$ sci_arttext\&pi$\mathrm{d}=\mathrm{S} 2223-25162020000100006 \& \operatorname{lng}=\mathrm{es} \& \mathrm{n}$ rm=iso. Acesso em: 4 jul. 2021.

BARROS, C. M. P. Responsabilidade social universitária: um estudo de caso no Curso de Medicina da Universidade Federal do Ceará - Campus de Sobral. 2009. 160 f. Dissertação (Mestrado em Políticas Públicas e Gestão da Educação Superior) - Universidade Federal do Ceará, Programa de Pós-graduação em Políticas Públicas e Gestão da Educação Superior, Fortaleza, 2009. Disponível em: http://www.repositorio.ufc.br/handle/ riufc/2663. Acesso em: 30 ago. 2019.

BARROS, C. M. P.; FREIRE, J. C. A responsabilidade social universitária na perspectiva do Sinaes: um estudo de caso no Curso de Medicina da Universidade Federal do Ceará - Campus de Sobral. Revista Ensaio: Avaliação e Políticas Públicas em Educação, Rio de Janeiro, v. 19, n. 73, p. 891-920, out. 2011. Disponível em: http:// revistas.cesgranrio.org.br/index.php/ensaio/article/view/421. Acesso em: 30 ago. 2019. 
BASTOS, F. S. A contribuição da universidade para a formação do sujeito moral. Práxis Educacional, Vitória da Conquista, v. 4, n. 5, p. 173-190, out. 2008. Disponível em: http:// periodicos2.uesb.br/index.php/praxis/article/ view/582. Acesso em: 10 set. 2019.

BERTO, A. B. F. Responsabilidade social universitária: princípios e valores em prol do desenvolvimento da comunidade. Humanas \& Sociais Aplicadas, v. 1, n. 2, p. 23-31 ago. 2011. Disponível em: https://ojs3.perspectivasonline.com.br/humanas_sociais_e_aplicadas/ article/view/229. Acesso em: 10 set. 2019.

BRASIL. Ministério da Educação. Fórum de Pró-Reitores de Extensão das Universidades Públicas. Brasileiras e SESu/MEC. 2000. Disponível em: https:/www.unifalmg.edu.br/ extensao/files/file/colecao_extensao_univeristaria/colecao_extensao_universitari a_1_planonacional.pdf. Acesso em: 10 nov. 2019.

BRASIL. Resolução ${ }^{0} 7$, de 18 de dezembro de 2018. Estabelece as Diretrizes para a Extensão na Educação Superior Brasileira. Diário Oficial [da] República Federativa do Brasil, Brasília, DF, 12 dez. 2018. Disponível em: http://www.in.gov.br/materia//asset_publisher/ Kujrw0TZC2Mb/content/id/55877808 . Acesso em: 14 nov. 2019.

CAPELETTE, M. C. F.; MAZZEI, B. B. A Universidade contribuindo na formação do cidadão através da Extensão Universitária: o caso específico do Projeto "Música, Poesia e Cidadania". Travessias (UNIOESTE. Online), v. 2, p. 1-23, 2007. Disponível em: http://e-revista.unioeste.br/index.php/travessias/article/ view/2902. Acesso em: 10 nov. 2019.

EIDT, E. C.; CALGARO, R. Responsabilidade social universitária: histórico e complexidade implícitos na constituição do conceito. Avaliação: Revista da Avaliação da Educação Superior, Campinas, v. 26, n. 1, p. 89-111, 2021. Disponível em: https://doi.org/10.1590/S141440772021000100006. Acesso em: 16 abr. 2021.
FREIRE, P. Conscientização: teoria e prática da libertação-uma introdução ao pensamento de Paulo Freire. São Paulo: Moraes, 1980.

GOERGEN, P. Universidade e compromisso social. In: RISTOFF, D.; SEVEGNANI, P. (org.). Universidade e compromisso social. Brasília: Instituto Nacional de Estudos e Pesquisas Educacionais Anísio Teixeira, 2006.

JORDÃO, C. Q. A responsabilidade social e cultura organizacional: impactos nas atitudes e nos comportamentos dos trabalhadores. R. Gest. Anál., Fortaleza, v. 8, n. 3, p. 22-45, set./dez. 2019. Disponível em: https://periodicos.unichristus.edu.br/gestao/article/view/2820/1035. Acesso em: 14 maio 2020.

JULIATTO, C. I. Universidade e solidariedade social: pegadas na areia global. Sei em quem confiei: festchrift em homenagem a Norberto Francisco Rauch. Porto Alegre: EDIPUCRS, 2004

KUIAVA, E. A. A responsabilidade como princípio ético em H. Jonas E. e Lévinas: uma aproximação. Revista Veritas, Porto Alegre, v. 51, n. 2, p. 55-60, 2006.

LÉVINAS, E. Entre nós: ensaios sobre a alteridade. Tradução de Pergentino Stefano Pivatto, Evaldo Antônio Kuiava, José Nedel, Luiz Pedro Wagner, Marcelo Luiz Pelizolli. 2. ed. Petrópolis: Vozes, 2005.

LÉVINAS, E. Da existência ao existente. Tradução Paul Albert Simon e Ligia Maria de Castro Simon. Campinas, São Paulo: Papirus, 1998.

LÉVINAS, E. Totalidade e infinito. Tradução José Pinto Ribeiro. Lisboa: Edições 70, 1980.

MORIN, E. O método 3: o conhecimento do conhecimento. Tradução Juremir Machado da Silva. 5. ed. Porto Alegre: Sulina, 2015.

PAPE, H. O poder do amor e a causalidade da mente: CS Peirce no lugar da mente e da cultura em evolução. Transactions of the Charles S. Peirce Society, 1997. 
PEIRCE, C. S. Immortality in the Light of Synechism. University. Amsterdam - Philadelphia, 1999.

PETERSON, M. A Universidade: da responsabilidade do corpo docente. In: DERRIDA, J. O olho da universidade. São Paulo: Estação Liberdade, 1999. p. 11-80.

PIVATTO, P. S. Apresentação. In: LÉVINAS, E. Entre nós: ensaios sobre a alteridade. Petrópolis: Vozes, 2005. p. 9-16.

SAVIANI, D. Extensão universitária: uma abordagem não-extensionista. In: SAVIANI, D. Ensino público e algumas falas sobre Universidade. São Paulo: Cortez/Autores Associados, 1984.

SILVA, T. T. As pedagogias psi e o governo do eu. In: SILVA, T. T. (org.). Liberdades reguladas: a pedagogia construtivista e outras formas de governo do eu. Petrópolis: Vozes, 1998. p. 7-13.

SOLIS, M. E.C. Identidad del sujeto educativo en la narrativa de la responsabilidad social universitaria. RIDE. Rev. Iberoam. Investig. Desarro. Educ, Guadalajara, v. 11, n. 21, e024, 2021. Disponível em: http:/www.scielo.org.mx/scielo.php?script=sci_arttext\&pi$\mathrm{d}=$ S007=74672020000200124-\&lng=es\&nrmiso. Acesso em: 5 jul. 2021.

SZYMANSKI, H. ALMEIDA, L. R; BRANDINI, R. C. A entrevista na educação: a prática reflexiva. 2. ed. Brasília: Liber Livro, 2004. v. 4.

VALLAEYS, F. Que significa responsabilidade social universitária. Revista da Associação Brasileira de Mantenedoras de Ensino Superior - Estudos, Brasília, v. 28, n. 36, p. 35-55, jun. 2006. Disponível em: http://www. abmes.org.br/Publicacoes/Estudos/36/index. asp. Acesso em: 15 nov. 2019.

VÁZQUEZ, A. S. Ética. Tradução João Dell'Anna. 29. ed. Rio de Janeiro: Civilização Brasileira, 2007.
VYGOTSKY, L. S. Teoria e método em psicologia. 3. ed. São Paulo: Martins Fontes, 2004.

ZULIANI, M. C. O conceito de consciência social na tese de Sinequismo de Charles $\mathrm{S}$. Peirce. 2011. 88 f. Dissertação (Mestrado em Filosofia) - Pontifícia Universidade Católica de São Paulo, São Paulo, 2011. Disponível em: https://tede2.pucsp.br/bitstream/handle/11592/1/ Maria\%20Conceicao\%20Zuliani.pdf. Acesso em: 20 nov. 2019. 